\title{
Thiazol-2-ylidenes: Versatile N-Heterocyclic Carbene Ligands with Enhanced Electrophilicity for Transition-Metal-Catalysis
}

Jin Zhang ( $\sim$ zhangjin@sust.edu.cn )

Shaanxi University of Science and Technology https://orcid.org/0000-0002-6616-7087

Tao Li

Shaanxi University of Science and Technology

Xiangyang Li

Shaanxi University of Science and Technology

Anqi Lv

Shaanxi University of Science and Technology

Xue Li

Shaanxi University of Science and Technology

\section{Zheng Wang}

Shaanxi University of Science and Technology

\section{Ruihong Wang}

Shaanxi University of Science and Technology

\section{Yangmin Ma}

Shaanxi Key Laboratory of Chemical Additives for Industry, College of Chemistry and Chemical Engineering, Shaanxi University of Science and Technology

\section{Ran Fang}

Lanzhou University

\section{Roman Szostak}

Wroclaw University

Michal Szostak

Rutgers, The State University of New Jersey https://orcid.org/0000-0002-9650-9690

\section{Article}

Keywords:

Posted Date: January 18th, 2022

DOI: https://doi.org/10.21203/rs.3.rs-1244443/v1 
License: (c) (i) This work is licensed under a Creative Commons Attribution 4.0 International License. Read Full License

Version of Record: A version of this preprint was published at Communications Chemistry on May 6th, 2022. See the published version at https://doi.org/10.1038/s42004-022-00675-7. 


\title{
Thiazol-2-ylidenes: Versatile N-Heterocyclic Carbene Ligands with Enhanced Electrophilicity for Transition-Metal-Catalysis
}

\author{
Jin Zhang, ${ }^{*}, 1$ Tao Li, ${ }^{1}$ Xiangyang Li,${ }^{1}$ Anqi Lv, ${ }^{1}$ Xue Li,${ }^{1}$ Zheng Wang, ${ }^{1}$ Ruihong Wang, ${ }^{2}$ Yangmin \\ Ma, ${ }^{1}$ Ran Fang, ${ }^{*, 1}$ Roman Szostak, ${ }^{3}$ and Michal Szostak*,4
}

\begin{abstract}
Affiliations
${ }^{1}$ College of Chemistry and Chemical Engineering, Key Laboratory of Chemical Additives for China National Light Industry, Shaanxi University of Science and Technology, Xi'an 710021, China

${ }^{2}$ Institute of Frontier Science and Technology Transfer, Shaanxi University of Science and Technology, Xi'an 710021, China

${ }^{3}$ Department of Chemistry, Wroclaw University, F. Joliot-Curie 14, Wroclaw 50-383, Poland

${ }^{4}$ Department of Chemistry, Rutgers University, 73 Warren Street, Newark, New Jersey 07102, United States

*zhangjin@sust.edu.cn; fangr@1zu.edu.cn; michal.szostak@ rutgers.edu
\end{abstract}

\begin{abstract}
Over the last 20 years, N-heterocyclic carbenes (NHCs) have emerged as a dominant direction in ligand development in transition-metal-catalysis. In particular, strong $\sigma$-donation in combination with tunable steric environment make NHCs to be among the most common ligands used for $\mathrm{C}-\mathrm{C}$ and $\mathrm{C}-$ heteroatom bond formation. Thus far, NHC ligand development has been almost exclusively limited to N-aryl-imidazolylidenes, such as IPr, prepared by deprotonation of symmetrical imidazolium salts. However, the molecular structure of imidazolylidene systems is constrained by the substitution with two nitrogen atoms, a limitation that prohibits the development of more active carbene
\end{abstract}


analogues. Herein, we report the first study on steric and electronic properties of thiazol-2-ylidenes. We demonstrate that the ring dissymmetry and enhanced $\pi$-electrophilicity result in a class of highly active carbene ligands for electrophilic cyclization reactions to form valuable oxazoline heterocycles. The evaluation of steric, electron-donating and $\pi$-accepting properties as well as structural characterization and coordination chemistry is presented. This mode of catalysis can be applied to late-stage drug functionalization to furnish attractive building blocks for medicinal chemistry. Considering the key role of N-heterocyclic ligands, we anticipate that $\mathrm{N}$-aryl thiazol-2-ylidenes will be of broad interest as ligands in modern chemical synthesis.

Article. Since the first successful isolation in $1991^{1}$ and the first use in catalysis in $1995,{ }^{2} \mathrm{~N}-$ heterocyclic carbenes (NHCs) have emerged as a powerful class of ligands in transition-metalcatalysis. ${ }^{3,4}$ The tremendous utility of NHCs hinges on strong $\sigma$-donation ${ }^{5}$ in combination with tunable steric environment, ${ }^{6}$ supercharging the catalytic activity of transition metals beyond other ligands. The most remarkable impact is in the development of Ru-catalyzed olefin metathesis ${ }^{7}$ and $\mathrm{Pd}$-catalyzed cross-couplings, ${ }^{8}$ where the strong $\sigma$-donation and high stability of $\mathrm{M}-\mathrm{C}_{(\mathrm{NHC})}$ bond render $\mathrm{NHCs}$ superior to the more ubiquitous phosphine ligands. Thus far, NHC ligand development in transitionmetal-catalysis has been almost exclusively limited to $\mathrm{N}$-aryl-imidazolylidenes $\mathbf{A},{ }^{4-8}$ such as $\operatorname{IPr},{ }^{9}$ prepared by deprotonation of symmetrical imidazolium salts (Figure 1). This is presumably due to enhanced electronic and steric stabilization of the carbene center by two nitrogen atoms as well as two $\mathrm{N}$-Ar wingtip substituents, which render $\mathrm{N}$-aryl-imidazolylidenes more stable and easier to handle. ${ }^{10}$ The pioneering studies by Bertrand and co-workers established that cyclic carbene systems with a marked decrease of heteroatom stabilization, such as CAACs B (cyclic (alkyl)amino)carbenes), ${ }^{11}$ are readily available, showing unique reactivity as supporting ligands in transition-metal-catalysis. More reactive and less stabilized systems, such as diamidocarbenes $\mathbf{C},{ }^{12}$ mesoionic carbenes $\mathbf{D}^{13}$ and remote carbenes $\mathbf{E},{ }^{14}$ have been developed, each class showing varying degrees of heteroatom stabilization and distinctive promise in transition-metal-catalysis. ${ }^{15}$ 


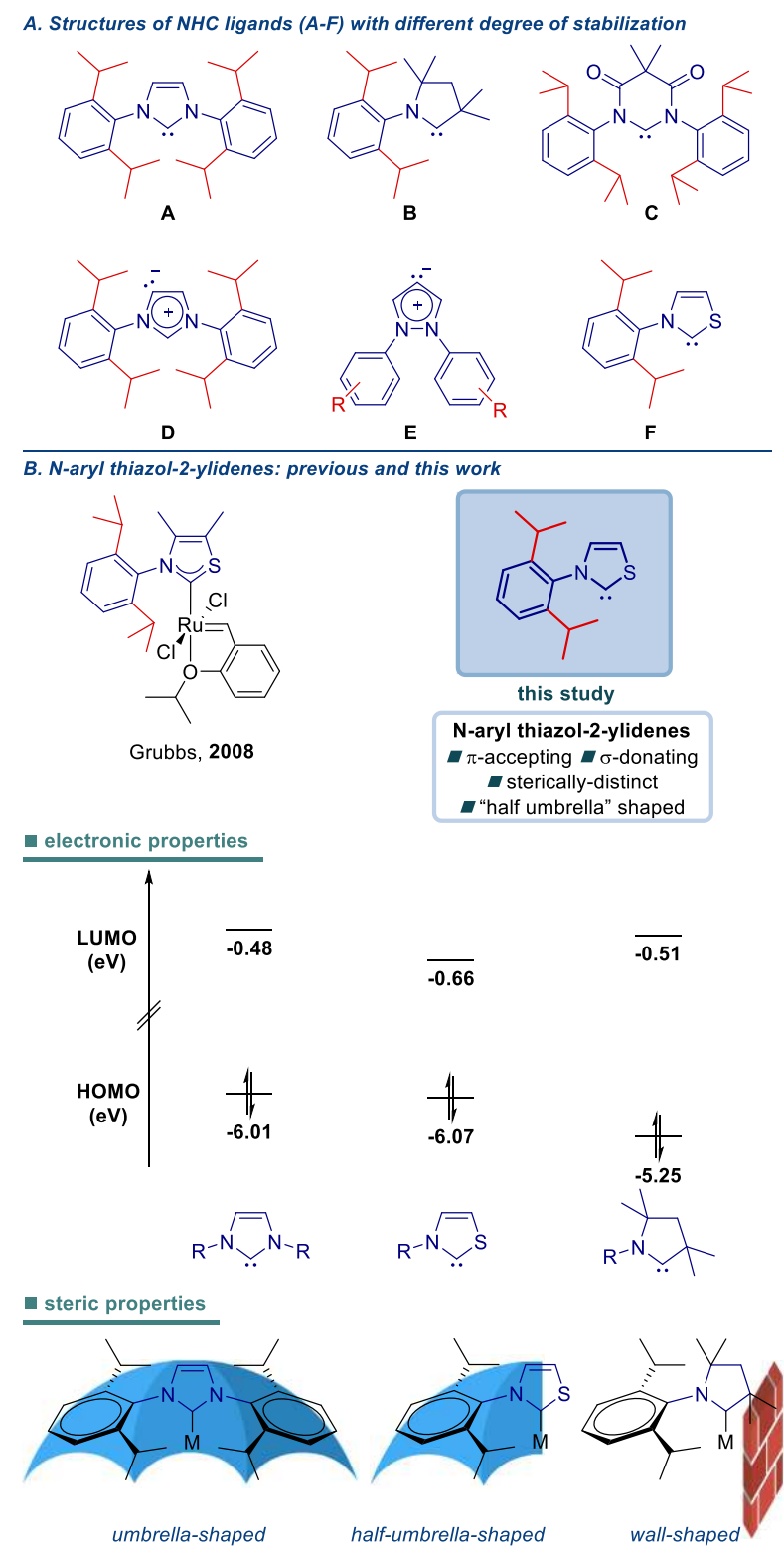

Figure 1. Structures of classical NHCs (A), CAACs (B), diamidocarbenes (C), mesoionic carbenes (D) and remote carbenes (E) with different degree of stabilization. Energies calculated at B3LYP 6$311++\mathrm{g}(\mathrm{d}, \mathrm{p})$ level, $\mathrm{R}=$ Dipp.

In this context, $\mathrm{N}$-aryl thiazol-2-ylidenes $\mathbf{F}$ are an intriguing class of $\mathrm{N}$-heterocyclic carbenes (Figure 1). Following the isolation of a stable thiazol-2-ylidene by Arduengo in 1997, ${ }^{16}$ this class of ligands stayed dormant until 2008, when Grubbs demonstrated the unique reactivity of Ru-based thiazol-2ylidene olefin metathesis catalysts. ${ }^{17}$ To our knowledge, this is the only application of N-aryl thiazol-2ylidene ligands in transition-metal-catalysis reported to date. ${ }^{18}$ More recently, there has been a resurgence of organocatalyzed radical relays and decarboxylative couplings made possible through the 
persistent radical stabilization by thiazol-2-ylidenes. ${ }^{19}$ In the meantime, studies by Boydston demonstrated organocatalyzed anodic oxidation of aldehydes through in situ generation of electroauxiliaries of thiazol-2-ylidenes, ${ }^{20}$ while the first characterization of elusive Breslow intermediates from thiazol-2-ylidenes by spectroscopic and crystallographic methods has been reported. $^{21}$

Biologically, thiazol-2-ylidenes are key intermediates in biochemical transformations of vitamin B1, ${ }^{22}$ including pyruvate decarboxylase, transketolase and dehydrogenase, a fact that spurred the interest in the burgeoning area of umpolung carbene reactivity. ${ }^{23}$

Geometrically, replacement of one of the nitrogen atoms in imidazol-2-ylidene systems with sulfur in thiazol-2-ylidenes results in disrupting the symmetrical ring geometry of imidazolylidenes. ${ }^{24}$ At the same time, there is a strong electronic effect in decreasing stabilization of the carbene center through diminished $\pi$ donation from sulfur. ${ }^{25}$ Finally, the sulfur atom does not bear any wingtip substituents that in imidazolylidene systems often provide a significant contribution to the stabilization of the carbene center. $^{4-8,24}$ These geometrical and electronic factors might explain why, with exception of the report by Grubbs, ${ }^{17} \mathrm{~N}$-aryl thiazol-2-ylidenes have been unexplored as NHC ligands in transition-metal-catalysis.

In terms of electronics, the diminished $\pi$ donation from sulfur due to unsymmetrical ring geometry and large sulfur radius is expected to result in more electrophilic carbenes than traditional imidazol-2ylidene systems, while maintaining strong donor ability (Figure 1). ${ }^{25}$

In terms of geometry, the effect of typical $\mathrm{NHC}$ ligands on $\mathrm{M}-\mathrm{C}_{(\mathrm{NHC})}$ bond is defined as "umbrella" shaped, in contrast to cone shaped phosphines (Figure 1). ${ }^{6}$ The combination of a nitrogen atom with a quaternary carbon in CAACs renders these ligands as "wall-shaped" with regard to the $\mathrm{M}-\mathrm{C}_{(\mathrm{NHC})}$ bond. ${ }^{11}$ The steric properties of N-aryl thiazol-2-ylidenes render these ligands "half umbrella" shaped with the nitrogen $\mathrm{N}$-wingtip oriented toward the $\mathrm{M}-\mathrm{C}_{(\mathrm{NHC})}$ bond and lack of substitution on the sulfur atom.

As a part of our interest in NHC catalysis, ${ }^{26}$ herein, we report the first study on steric and electronic properties of thiazol-2-ylidenes. Most importantly, we demonstrate that the ring dissymmetry and enhanced $\pi$-electrophilicity result in a class of highly active carbene ligands that supersede imidazol-2- 
ylidenes. We present the evaluation of steric, electron-donating and $\pi$-accepting properties as well as structural characterization and coordination chemistry. Considering the key role of N-heterocyclic ligands, we envision that $\mathrm{N}$-aryl thiazol-2-ylidenes will be of broad interest as ligands in chemical synthesis.

$\mathrm{N}$-Aryl thiazol-2-ylidenes carbene precursors are readily available on multigram scale following the aforementioned protocols for organocatalytic transformations (see SI). ${ }^{19}$ Four N-aryl thiazol-2-ylidenes carbene precursors were selected as a starting point (Scheme 1). For the study, we chose structural sulfur analogues of IPr and IMes on 3-aryl-4,5-dimethylthiazol-2-ylidene framework; MeIPrS and MeIMesS. IPr ligand (IPr = 1,3-bis(2,6-diisopropylphenyl)imidazol-2-ylidene; N-Dipp, Dipp = 2,6diisopropylphenyl) is by far the most common NHC ligand used in transition-metal-catalysis, while its smaller IMes $(\mathrm{IMes}=$ 1,3-bis(2,4,6-trimethylphenyl)imidazol-2-ylidene, N-Mes, Mes = 2,4,6trimethylphenyl) counterpart is often used for transformations requiring lower steric demand of the Nwingtip substituents. Furthermore, 3-aryl-4,5-cyclohexylthiazol-2-ylidene and 3-aryl-4,5cycloheptylthiazol-2-ylidene, ${ }^{6} \mathbf{I P r S}$ and ${ }^{7} \mathbf{I P r S}$ were selected on the basis of the recent reports in organocatalytic transformations, ${ }^{19}$ where the fused cyclic ring on the backbone of N-aryl thiazol-2ylidenes often provided advantageous stability of the system.

Scheme 1. Synthesis of Thiazol-2-ylidene Precursors ${ }^{a}$

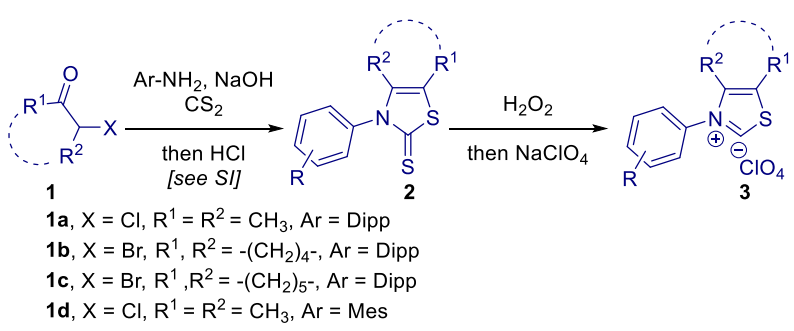

${ }^{\text {a See SI. }}$

With access to $\mathrm{N}$-aryl thiazol-2-ylidene precursors, we next prepared $\mathrm{Ag}(\mathrm{I})$ complexes $\left[\mathrm{Ag}(\mathbf{N H C})_{2}\right]\left(\mathrm{ClO}_{4}\right) \mathbf{4 a - 4 d}$ by the reaction with $\mathrm{Ag}_{2} \mathrm{O}$ in $\mathrm{CH}_{2} \mathrm{Cl}_{2}$ (Scheme 2). Interestingly, complexes 4a-4c $\left(\left[\mathrm{Ag}\left({ }^{\mathrm{Me}} \mathbf{I P r S}\right)_{2}\right]\left(\mathrm{ClO}_{4}\right)(\mathbf{4 a}),\left[\mathrm{Ag}\left({ }^{6} \mathbf{I P r S}\right)_{2}\right]\left(\mathrm{ClO}_{4}\right)(\mathbf{4 b})\right.$ and $\left.\left[\mathrm{Ag}\left({ }^{7} \mathbf{I P r S}\right)_{2}\right]\left(\mathrm{ClO}_{4}\right)(\mathbf{4 c})\right)$ were found to be stable to air and moisture and could be fully characterized by X-ray crystallography (Figure 2, vide 
infra). In contrast, the less sterically-hindered $\mathrm{Ag}(\mathrm{I})$ complex $\mathbf{4 d}\left[\mathrm{Ag}(\mathbf{M e} \mathbf{I M e s S})_{2}\right]\left(\mathrm{ClO}_{4}\right)$ was found to be significantly less stable. This finding mirrors the study by Arduengo, ${ }^{16}$ who found that small N-wingtip substituents in thiazol-2-ylidene systems result in unstable carbenes. Unsurprisingly, the "halfumbrella" shape of $\mathrm{N}$-aryl thiazol-2-ylidenes requires larger groups at the nitrogen atom for easy handling and isolation. Likewise, we found that the formation of bis-NHC-Ag(I) is needed to prevent decomposition of monomeric $\mathrm{Ag}(\mathrm{I})-\mathrm{NHCs}$ in these thiazol-2-ylidene systems. From the outset, we were interested in $\mathrm{Ag}(\mathrm{I})-\mathrm{NHC}$ complexes because of the untapped potential of $\mathrm{Ag}(\mathrm{I})-\mathrm{NHC}$ complexes in catalysis as compared to other coinage metals. ${ }^{27}$

Scheme 2. Synthesis of $\operatorname{Ag}(\mathrm{I})$ Complexes $^{a}$
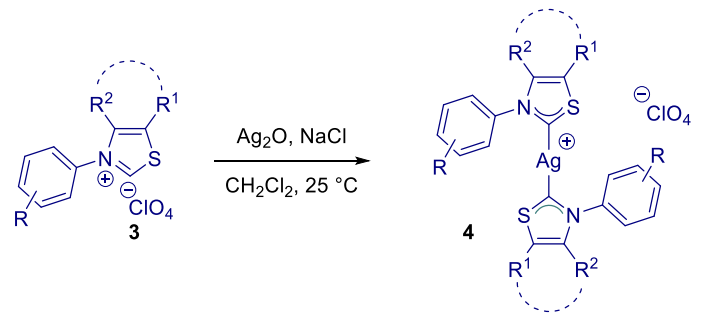

${ }^{a}$ Conditions: $\mathrm{Ag}_{2} \mathrm{O}$ (0.5 equiv), $\mathrm{NaCl}$ (2.0 equiv), $\mathrm{CH}_{2} \mathrm{Cl}_{2}, 25{ }^{\circ} \mathrm{C}, 16$ h, 4a: $96 \% ; \mathbf{4 b}: 95 \%$; 4 c: $97 \%$; 4 d: $90 \%$.

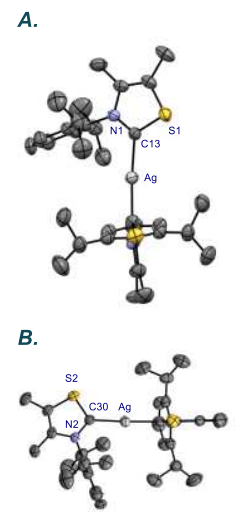

(4a)
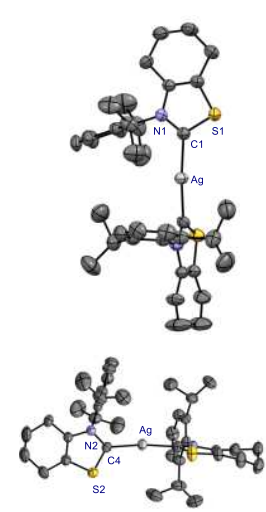

$(\mathbf{4 b})$

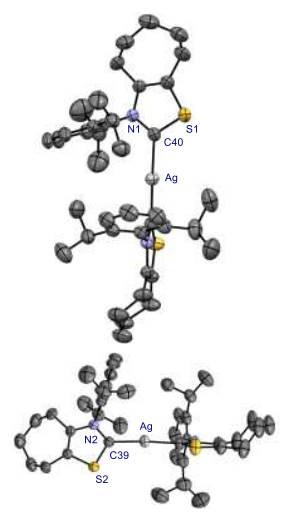

(4c)

Figure 2. X-ray crystal structure of $\mathrm{Ag}(\mathrm{I})$ complexes 4a-4c. Two views: front (top); side (bottom). Hydrogen atoms and counterion have been omitted for clarity. Selected bond lengths $[\AA]$ and angles $\left[^{\circ}\right]$ : 4a: Ag-C13, 2.082(3); Ag-C30, 2.086(3); N1-C13, 1.335(4); N2-C30, 1.337(4); S1-C13, 1.703(3); S2-C30, 1.697(3); C13-Ag-C30, 175.0(1). 4b: Ag-C1, 2.075(4); Ag-C4, 2.078(4); N1-C1, 1.342(6); N2-C4, 1.331(6); S1-C1, 1.691(5); S2-C4, 1.693(6); C1-Ag-C4, 172.2(2). 4c: Ag-C40, 2.087(2); Ag- 
C39, 2.081(3); N1-C40, 1.339(3); N2-C39, 1.336(3); S1-C40, 1.699(4); S2-C39, 1.704(3); C40-AgC39, 175.5(1). 4a: CCDC 2117719; 4b: CCDC 2117722; 4c: CCDC 2117721.

We next comprehensively evaluated steric and electronic properties of these N-aryl thiazol-2-ylidene ligands. As shown in Scheme 3, the linear copper(I) complex [Cu(MeIPrS)Cl] (5a) was prepared after deprotonation with an excess of $\mathrm{KO} t$-Bu (2 equiv), while $\mathrm{Rh}(\mathrm{I})$ complexes, $\left[\mathrm{Rh}\left({ }^{\mathbf{6}} \mathbf{I P r S}\right)(\mathrm{CO}){ }_{2} \mathrm{Cl}\right](\mathbf{6 b})$ and $\left[\mathrm{Rh}\left({ }^{7} \mathbf{I P r S}\right)(\mathrm{CO})_{2} \mathrm{Cl}\right](\mathbf{6 c})$ were prepared by a two-step procedure via $[\mathrm{Rh}(\mathbf{N H C})(\mathrm{cod}) \mathrm{Cl}]$ and the reaction with carbon monoxide. We have also prepared the selenium adducts $[\operatorname{Se}(\mathbf{N H C})](\mathbf{5 a - 5 d})$ by adding the free carbene generated in situ to excess of selenium.

Scheme 3. Synthesis of Thiazol-2-ylidene Complexes ${ }^{a}$

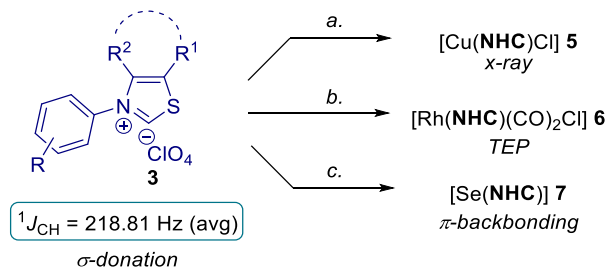

${ }^{a}$ Conditions: (a) $\mathrm{CuCl}$ (1.1 equiv), $\mathrm{KO}$-Bu (1.0 equiv), THF, $25^{\circ} \mathrm{C}, 16 \mathrm{~h}, 59 \%, 5 a, \mathrm{CCDC} 2117739$. (b) $[\mathrm{Rh}(\mathrm{cod}) \mathrm{Cl}]_{2}\left(1.0\right.$ equiv), $\mathrm{KO} t$-Bu $\left(2.0\right.$ equiv), $\mathrm{THF}, 23{ }^{\circ} \mathrm{C}, 8 \mathrm{~h}$, then $\mathrm{CO}, \mathrm{CH}_{2} \mathrm{Cl}_{2}, 0{ }^{\circ} \mathrm{C}, 1 \mathrm{~h}, 95 \%, 6 \mathbf{b}$; 96\%, 6c. (c) Se (1.5 equiv), $\mathrm{KOt}$-Bu (1.2 equiv), THF, $25{ }^{\circ} \mathrm{C}, 12 \mathrm{~h}, 95 \%, 7 \mathbf{a} ; 96 \%, 7 \mathbf{b} ; 93 \%, 7 \mathbf{c} ; 93 \%$, $7 d$.

$\mathrm{Cu}(\mathrm{I})-\mathrm{NHC}$ complex [Cu(MeIPrS)Cl] (5a) was fully characterized by X-ray crystallography (Figure 3). Studies by Cavallo and co-workers demonstrated that catalytic pockets of $\mathrm{M}-\mathrm{NHCs}$ are best described by the $\%$ buried volume $\left(\% \mathrm{~V}_{b u r}\right)$ of model linear $[\mathrm{M}(\mathrm{NHC}) \mathrm{Cl}]$ complexes. ${ }^{28}$ Complex $\left[\mathrm{Cu}\left({ }^{\mathrm{Me}} \mathbf{I P r S}\right) \mathrm{Cl}\right](\mathbf{5 a})$ is linear $\left(\mathrm{C}_{(\mathrm{NHC})}-\mathrm{Cu}-\mathrm{Cl}, 177.0^{\circ} ; \mathrm{C}-\mathrm{Cu}, 1.871 \AA\right)$, making it a good model for evaluating $\% \mathrm{~V}_{\text {bur }}$ of $\mathrm{N}$-aryl thiazol-2-ylidene ligands. Thus, the $\left(\% \mathrm{~V}_{\text {bur }}\right)$ of $(\mathbf{5 a})$ is $37.0 \%$, which can be compared with the $\left(\% \mathrm{~V}_{\text {bur }}\right)$ of $47.6 \%$ determined for $[\mathrm{Cu}(\mathbf{I P r}) \mathrm{Cl}]\left(\mathrm{C}-\mathrm{Cu}-\mathrm{Cl}, 176.7^{\circ} ; \mathrm{C}-\mathrm{Cu}, 1.881 \AA\right) .{ }^{29}$ A graphical representation of the steric mapping is shown in Figure 3B. Importantly, the X-ray crystallographic analysis revealed the $\left(\% \mathrm{~V}_{b u r}\right)$ of $50.2 \%, 52.0 \%, 22.6 \%, 23.1 \%$ for each quadrant (Figure 3). The values can be compared with the $\left(\% \mathrm{~V}_{b u r}\right)$ of $55.5 \%, 39.6 \%, 39.6 \%, 55.5 \%$ for each 
quadrant of $[\mathrm{Cu}(\mathbf{I P r}) \mathrm{Cl}]$, revealing a "half-umbrella" steric arrangement of $\mathrm{N}$-aryl thiazol-2-ylidene ligands.
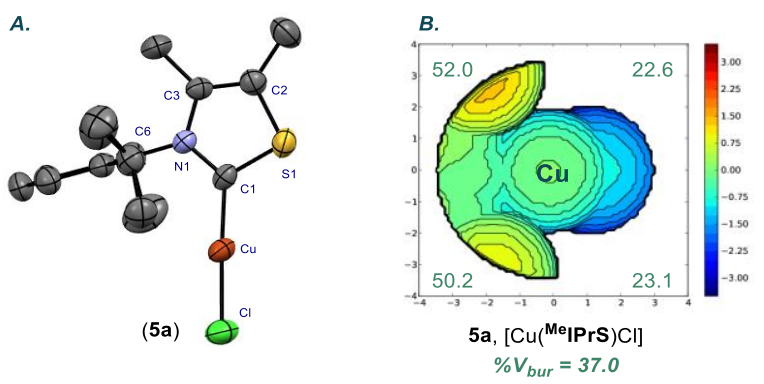

Figure 3. (a) X-ray crystal structure of complex 5a. Hydrogen atoms have been omitted for clarity. Selected bond lengths $[\AA]$ and angles $\left[{ }^{\circ}\right]: \mathrm{Cu}-\mathrm{C} 1,1.871(2) ; \mathrm{Cu}-\mathrm{Cl}, 2.0947(7) ; \mathrm{C} 1-\mathrm{N} 1,1.338(2)$; $\mathrm{C} 1-\mathrm{S} 1$, 1.700(2); C6-N1, 1.460(3); N1-C3, 1.402(3); S1-C2, 1.723(2); C1-Cu-Cl, 176.98(7); N1-C1-S1, 107.3(1); C6-N1-C1, 121.3(2); C3-N1-C1, 117.0(2); C2-S1-C1, 94.5(1). (b) Topographical steric map of $\left[\mathrm{Cu}\left({ }^{\mathrm{Me}} \mathbf{I P r S}\right) \mathrm{Cl}\right]$ (5a) showing \% Vur per quadrant. CCDC 2117739. Note dissymmetry of the ring.

The Tolman electronic parameter (TEP) has been determined from the $\mathrm{CO}$ stretching frequencies of $\left[\mathrm{Rh}\left({ }^{7} \mathbf{I P r S}\right)(\mathrm{CO})_{2} \mathrm{Cl}\right]$ of $v_{\text {sym }}=2078.0 \mathrm{~cm}^{-1}$ and $v_{\text {asym }}=2001.4 \mathrm{~cm}^{-1}\left(\mathrm{CH}_{2} \mathrm{Cl}_{2}, 0.20 \mathrm{M}\right)$, respectively. This corresponds to a TEP of $2051.9 \mathrm{~cm}^{-1}$ as a combined measure of the electronic properties of $\mathrm{N}$-aryl thiazol-2-ylidene ligands. ${ }^{30}$ These values can be compared with the classical imidazol-2-ylidene IPr (TEP of $2051.5 \mathrm{~cm}^{-1}$ ) and a model cyclic (alkyl)amino)carbene CAAC ${ }^{\mathrm{Cy}}$ (TEP of $2048.6 \mathrm{~cm}^{-1}$ ), ${ }^{11 \mathrm{a}}$ indicating strong donor ability of N-aryl thiazol-2-ylidenes.

In the same vein, selenourea adducts allow to determine $\pi$-backbonding of NHC ligands from the ${ }^{77} \mathrm{Se}$ NMR spectra. ${ }^{31}$ As such, the $\delta$ Se values of 375.99 ppm for [Se(MeIPrS)] and $374.88 \mathrm{ppm}, 366.70 \mathrm{ppm}$, 329.96 for $\left[\mathrm{Se}\left({ }^{6} \mathbf{I P r S}\right)\right],\left[\operatorname{Se}\left({ }^{7} \mathbf{I P r S}\right)\right]$, [Se(MeIMesS $\left.)\right]\left(\mathrm{CDCl}_{3}\right)$, respectively, indicate significantly better $\pi$-acceptance of $\mathrm{N}$-aryl thiazol-2-ylidenes than imidazol-2-ylidene, $\operatorname{IPr}\left(\delta_{\mathrm{Se}}=90 \mathrm{ppm}\right)$, as expected from the sulfur substitution.

Moreover, one-bond $\mathrm{CH} \mathrm{J}$ coupling constants from ${ }^{13} \mathrm{C}$ satellites of the ${ }^{1} \mathrm{H}$ NMR spectrum give a good prediction of $\sigma$-donating properties of NHC ligands. ${ }^{32}$ The values of $218.70 \mathrm{~Hz}$ for Me IPrS and 218.34 $\mathrm{Hz}, 218.82 \mathrm{~Hz}, 219.36 \mathrm{~Hz}$ for ${ }^{6} \mathbf{I P r S},{ }^{7} \mathbf{I P r S}$, and ${ }^{\mathbf{M}} \mathbf{I M e s S}\left(\mathrm{HClO}_{4}\right.$ salts, $\left.\mathrm{CDCl}_{3}\right)$, respectively, are 
consistent with $\mathrm{N}$-aryl thiazol-2-ylidenes as strongly $\sigma$-donating NHC ligands, which can be compared with imidazol-2-ylidene $\operatorname{IPr}\left({ }^{1} J_{\mathrm{CH}}=223.70 \mathrm{~Hz}\right)$. However, at the same time, N-aryl thiazol-2-ylidenes are significantly more $\pi$-accepting and feature a distinct "half-umbrella" steric impact.

With structural and electronic characterization of $\mathrm{N}$-aryl thiazol-2-ylidenes, we next evaluated the activity of Ag(I)-thiazol-2-ylidene complexes in catalysis (Table 1, and Schemes 4-5). As stated above, we selected $\mathrm{Ag}(\mathrm{I})-\mathrm{NHC}$ complexes because $\mathrm{Ag}(\mathrm{I})$ complexes have been much less explored in catalysis than other group 11 metals $^{27}$ as well as to probe electrophilic $\pi$-activation of the ligands. Electrophilic $O$-cyclization of N-propargylic amides was selected as a model reaction due to the importance of the product oxazoline heterocycles in medicinal chemistry research. ${ }^{33}$ As shown, the reaction proceeds under very mild conditions using bis-NHC-Ag(I) salts 4a-d (5-10 mol\%) in the presence of $\mathrm{AcOH}$ in $\mathrm{CH}_{2} \mathrm{Cl}_{2}$ at room temperature (Table 1, entries 1-8, see $\mathrm{SI}$ for details). $\mathrm{AcOH}$ is required as an additive (vide infra). ${ }^{34}$ Likewise, no reaction takes place in the absence of $\mathrm{N}$-aryl thiazol-2-ylidene $\operatorname{Ag}(\mathrm{I})$ complexes (Table 1, entries 9-10). Out of the complexes 4a-d, the cycloheptyl complex $\left[\mathrm{Ag}\left({ }^{7} \mathbf{I P r S}\right)_{2}\right]\left(\mathrm{ClO}_{4}\right)$ showed the highest reactivity and was selected for scope studies. The loading could be further decreased to $1 \mathrm{~mol} \%$ with excellent efficiency (>95\%) (Table 1, entries 11-14). Most importantly, the use of classical imidazol-2-ylidene complexes $[\mathrm{Ag}(\mathrm{IPr}) \mathrm{Cl}]$ and $[(\mathrm{Ag}(\mathrm{IMes}) \mathrm{Cl}]$ resulted in negligible reactivity (7-16\%) (Table 1, entries 15-16), indicating superior reactivity of N-aryl thiazol2-ylidenes. Additional studies to eliminate the effect of counterion further demonstrate the superior effect of N-aryl thiazol-2-ylidene $\mathrm{Ag}(\mathrm{I})$ complexes (see SI). ${ }^{35}$

Table 1. Optimization of Ag-NHC-Catalyzed Cyclization of N-Propargylic Amides ${ }^{a}$

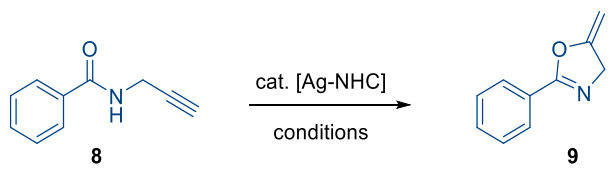

\begin{tabular}{cllcc}
\hline entry & catalyst & additive & mol\% & yield (\%) \\
\hline 1 & $\mathbf{4 a}$ & $\mathrm{CH}_{3} \mathrm{CO}_{2} \mathrm{H}$ & 10 & 90 \\
2 & $\mathbf{4 b}$ & $\mathrm{CH}_{3} \mathrm{CO}_{2} \mathrm{H}$ & 10 & 95 \\
3 & $\mathbf{4 c}$ & $\mathrm{CH}_{3} \mathrm{CO}_{2} \mathrm{H}$ & 10 & 98
\end{tabular}




$\begin{array}{lllll}4 & \mathbf{4 d} & \mathrm{CH}_{3} \mathrm{CO}_{2} \mathrm{H} & 10 & 96 \\ 5 & 4 \mathbf{a} & \mathrm{CH}_{3} \mathrm{CO}_{2} \mathrm{H} & 5 & 90 \\ 6 & 4 \mathbf{b} & \mathrm{CH}_{3} \mathrm{CO}_{2} \mathrm{H} & 5 & 93 \\ 7 & \mathbf{4 c} & \mathrm{CH}_{3} \mathrm{CO}_{2} \mathrm{H} & 5 & 96 \\ 8 & 4 \mathbf{d} & \mathrm{CH}_{3} \mathrm{CO}_{2} \mathrm{H} & 5 & 91 \\ 9 & - & \mathrm{CH}_{3} \mathrm{CO}_{2} \mathrm{H} & - & - \\ 10 & 4 \mathbf{a}-\mathbf{4 d} & - & 10 & - \\ 11 & 4 \mathbf{a} & \mathrm{CH}_{3} \mathrm{CO}_{2} \mathrm{H} & 1 & 88 \\ 12 & 4 \mathbf{b} & \mathrm{CH}_{3} \mathrm{CO}_{2} \mathrm{H} & 1 & 85 \\ 13 & 4 \mathbf{c} & \mathrm{CH}_{3} \mathrm{CO}_{2} \mathrm{H} & 1 & >95 \\ 14 & 4 \mathbf{4 d} & \mathrm{CH}_{3} \mathrm{CO}_{2} \mathrm{H} & 1 & 87 \\ 15 & {[\mathrm{Ag}(\mathrm{IPr}) \mathrm{Cl}]} & \mathrm{CH}_{3} \mathrm{CO}_{2} \mathrm{H} & 10 & 16 \\ 16 & {[\mathrm{Ag}(\mathrm{IMes}) \mathrm{Cl}]} & \mathrm{CH}_{3} \mathrm{CO}_{2} \mathrm{H} & 10 & 7\end{array}$

${ }^{a}$ Conditions: 8 (1.0 equiv), $\mathrm{Ag}-\mathrm{NHC}$ ([Ag], 1-10 mol\%), additive (1.0 equiv), $\mathrm{CH}_{2} \mathrm{Cl}_{2}(1.0 \mathrm{M}), 25^{\circ} \mathrm{C}, 8$ h. See SI for details.

Having established the optimal conditions for electrophilic cyclization using N-aryl-thiazol-2ylidene- $\operatorname{Ag}(\mathrm{I})$ complexes, next the scope was examined (Scheme 4).

As shown, the scope of the reaction is very broad and encompasses a variety of $\mathrm{N}$-propargylic amides (Scheme 4). As such, aromatic amides with neutral (9a), electron-donating (9b-9f), electronwithdrawing (9g-9n) substituents at the para, ortho and meta positions could be successfully reacted to give diverse 2-aryl-2-oxazolines. Importantly, medicinally-relevant substituents, such as 3,4,5trimethoxyphenyl (9f), nitro $(\mathbf{9 g})$, cyano $(\mathbf{9 h})$, trifluoromethyl $(\mathbf{9 i - 9 j})$ as well as halide functional handles that enable further derivatization $(\mathbf{9 j}-\mathbf{9 n})$ were well compatible with the reaction. Furthermore, $\pi$-conjugated substituents, such as naphthyl (9o) and cinnamyl (9p) furnished the products in high yields. Heterocyclic amides, such as 2-thienyl (9q) were well tolerated. Interestingly, highly selective monocyclization is possible using meta-substituted propargylic diamide (9r). Pleasingly, aliphatic amides with $\alpha$-branching $(9 \mathbf{s})$ as well as $1^{\circ}(9 \mathbf{t}, 9 \mathbf{w}), 2^{\circ}(9 \mathbf{v})$, and $3^{\circ}$ sterically-hindered aliphatic amides $(9 \mathbf{u})$ are 
tolerated in this process despite the lack of $\mathrm{Ar} \rightarrow \pi^{*} \mathrm{C}=\mathrm{O}$ conjugation with the amide oxygen atom. Furthermore, substitution at the methylene carbon adjacent to the nitrogen to deliver 4-substitued oxazolines is also compatible (9x-9aa), increasing the overall synthetic utility of the process. Further, substitution of the alkyne is tolerated without loss in reaction efficiency (9ab-9ad), furnishing fully substituted oxazolines. The product 9ad was crystalline and the structure was confirmed by x-ray crystallography, indicating $(Z)$-geometry of the double bond ( $\mathrm{dr}>98: 2)$. This result is consistent with an anti-attack of the amide bond oxygen on the $\mathrm{Ag}(\mathrm{I})-\mathrm{NHC}-\pi$-activated alkyne (vide infra).

Scheme 4. Scope of Ag-NHC-Catalyzed Cyclization of N-Propargylic Amides ${ }^{a}$

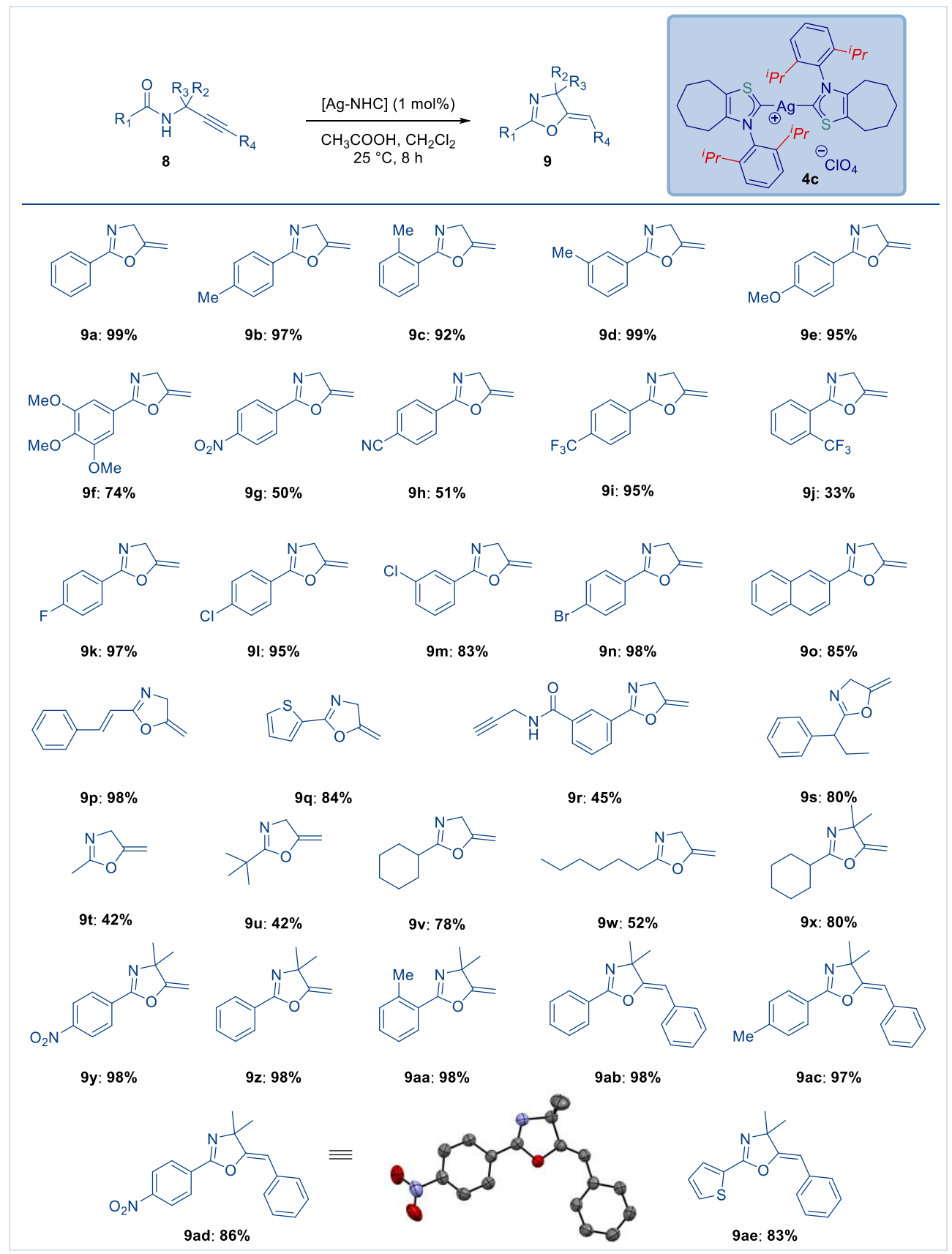


${ }^{a}$ Conditions: amide (1.0 equiv), catalyst $4 \mathbf{c}$ ([Ag], 1 mol\%), $\mathrm{CH}_{3} \mathrm{CO}_{2} \mathrm{H}$ (1.0 equiv), $\mathrm{CH}_{2} \mathrm{Cl}_{2}(1.0 \mathrm{M})$, $25^{\circ} \mathrm{C}, 8 \mathrm{~h}$. See SI for details, 9ad: CCDC: 2125052.

Most crucially, the mild reaction conditions enabled by the $\mathrm{N}$-aryl thiazol-2-ylidene ligands permit this mode of catalysis to be applied to late-stage functionalization to furnish attractive heterocyclic building blocks for medicinal chemistry and agrochemistry research (Scheme 5). Thus, electrophilic cyclization of propargylic amides from acifluorfen (9af, protoporphyrinogen oxidase inhibitor), piperonylic acid (9ag, trans-cinnamate hydroxylase inhibitor), dicamba (9ah, broad spectrum herbicide), febuxostat (9ai, antigout) and probenecid (9aj, antihyperuricemic) delivered cyclization products in good to high yields without modification of the reaction conditions. This successful late-stage diversification highlights the mild conditions of the present protocol with tolerance to an array of sensitive functional groups (halides, cyano, nitro, sulfonamide, aryl ethers, S-heterocycles), demonstrating prospective impact on medicinal chemistry research.

Scheme 5. Late-Stage Functionalization in Ag-NHC-Catalyzed Cyclization of N-Propargylic Amides ${ }^{a}$

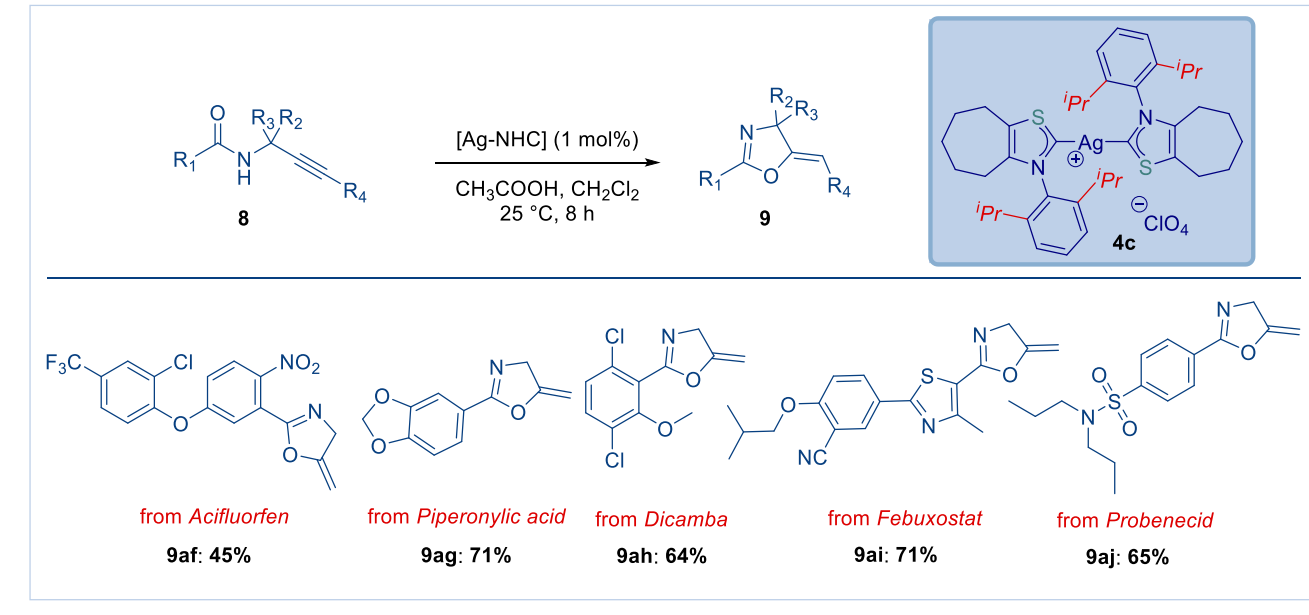

${ }^{a}$ Conditions: amide (1.0 equiv), catalyst $4 \mathrm{c}$ ([Ag], $\left.1 \mathrm{~mol} \%\right), \mathrm{CH}_{3} \mathrm{CO}_{2} \mathrm{H}$ (1.0 equiv), $\mathrm{CH}_{2} \mathrm{Cl}_{2}(1.0 \mathrm{M})$, $25^{\circ} \mathrm{C}, 8 \mathrm{~h}$. See SI for details.

To gain insight into the reaction mechanism of this intriguing transformation, catalytic cycle was studied by DFT computations (Figure 4). Based on the previous work, ${ }^{34}$ our calculation results show that the catalytic cycles for these processes are comprised of three key steps. In the first step, $\mathrm{L}_{2} \mathrm{Ag}$ will give active catalyst $\mathbf{1}$ ' in the presence of $\mathrm{AcOH}$. The free energy of activation for this step is 20.1 $\mathrm{kcal} / \mathrm{mol}$ for TS1 (Figure 4). After formation of active catalyst 1, the ligand exchange between $\mathrm{AcO}^{-}$and 
amide $\mathbf{R e}$ would give intermediate $\mathbf{2}$ with a free energy release of $-6.7 \mathrm{kcal} / \mathrm{mol}$. In second step, $\mathbf{2}$, would generate putative vinyl-silver intermediate 3' by a 5-exo-dig cyclisation. The free energy of activation for TS2 $(Z)$ and TS22 $(E)$ is 12.7 and $19.6 \mathrm{kcal} / \mathrm{mol}$, respectively. This calculation result for $Z / E$ selectivity is fully consistent with the experiments results. The final step involves a 1,4-H shift that leads to the final product P1. First, two- and three-molecule HOAc-assisted 1,4-H shift (TS31 and TS32) were calculated. The calculated activation free energy of TS31 and TS32 is high (27.4 and 24.5 $\mathrm{kcal} / \mathrm{mol}$, page S142, SI) to occur under the experimental conditions. Another possible pathway involves HOAc and ligand assisted 1,4-H shift. In this pathway, coordination of HOAc and ligand with 3' would generate intermediate 4' with a free energy release of $-10.0 \mathrm{kcal} / \mathrm{mol}$. The protodemetallation step would form the product $\mathbf{P 1}$ and regenerate the silver catalyst and HOAc. This step is exergonic by $30.6 \mathrm{kcal} / \mathrm{mol}$ and the free energy barrier is $15.8 \mathrm{kcal} / \mathrm{mol}$.

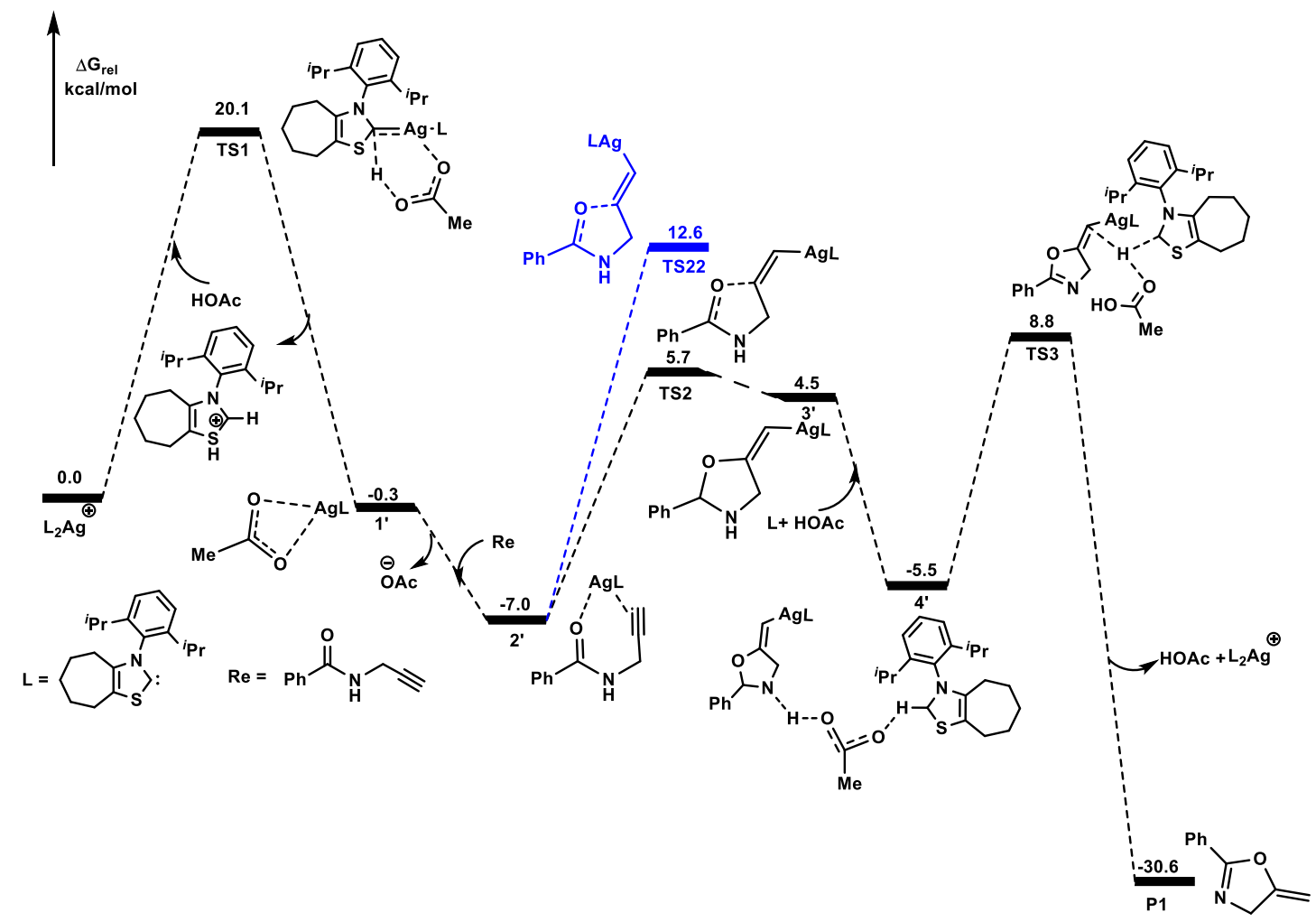

Figure 4. DFT-computed free energy profile of $\mathrm{Ag}-\mathrm{NHC}$ catalyzed cyclization of N-propargylic amides. See SI for computational details.

To further evaluate the effect of nitrogen to sulfur replacement in N-aryl thiazol-2-ylidenes, HOMO and LUMO energy levels of carbenes MeIPrS, ${ }^{6} \mathbf{I P r S},{ }^{7} \mathbf{I P r S}$ and MeIMesS were determined at the 
B3LYP 6-311++g(d,p) level (Figure 5 and SI). It is now recognized that the donating ability of carbenes is closely associated with the HOMO orbital, while the electron acceptance is associated with the LUMO orbital. ${ }^{5,11,30}$ Computation of frontier orbitals represents the most accurate evaluation of nucleophilicity (higher HOMO) and electrophilicity (lower LUMO) of NHC ligands, ${ }^{5,11,30}$ while the comparison must be available at the same level of theory.

The HOMO of MeIPrS (-6.07 eV, $\sigma$-bonding orbital) is comparable with IPr $(-6.01 \mathrm{eV})$, which is a routine model for $\sigma$-donating NHCs. The HOMO of ${ }^{6} \mathbf{I P r S},{ }^{7} \mathbf{I P r S}$ and ${ }^{\mathrm{Me}} \mathbf{I M e s}$ are $-6.05 \mathrm{eV},-5.99 \mathrm{eV},-$ $6.02 \mathrm{eV}$ respectively, indicating that these N-aryl thiazol-2-ylidenes are similarly strongly nucleophilic as N-aryl-imidazol-2-ylidenes. Furthermore, the LUMO of MeIPrS (-0.66 eV, $\pi$-accepting orbital) is significantly lower than for the standard imidazol-2-ylidene ligands IMes $(-0.33 \mathrm{eV}), \mathbf{I P r}(-0.48 \mathrm{eV})$ of the corresponding $\pi$-accepting orbitals. The LUMO of ${ }^{6} \mathbf{I P r S},{ }^{7} \mathbf{I P r S}$ and ${ }^{\mathrm{Me}} \mathbf{I M}$ MesS are $-0.67 \mathrm{eV},-0.68$ $\mathrm{eV},-0.53 \mathrm{eV}$, respectively (MeIMesS, LUMO+1 due to required symmetry), indicating that $\mathrm{N}$-aryl thiazol-2-ylidenes are significantly better $\pi$-acceptors than the standard imidazolylidene IMes and IPr ligands. In addition, the HOMO-1 ( $\pi$-donating orbital) in the series of ${ }^{\text {MeIPrS, }}{ }^{6} \mathbf{I P r S},{ }^{7} \mathbf{I P r S}$ and MeIMesS is $-6.57 \mathrm{eV},-6.49 \mathrm{eV},-6.44 \mathrm{eV},-6.51 \mathrm{eV}$, which is in the same range as for the $\pi$-donating orbital for the standard imidazolylidene IMes $(-6.44 \mathrm{eV})$ and IPr $(-6.55 \mathrm{eV})$ determined at the same level of theory. Overall, $\mathrm{N}$-aryl thiazol-2-ylidenes can be characterized as $\pi$-accepting, $\sigma$-donating and sterically-distinct "half umbrella" shaped ligands that are well-poised for electrophilic catalysis. ${ }^{36}$
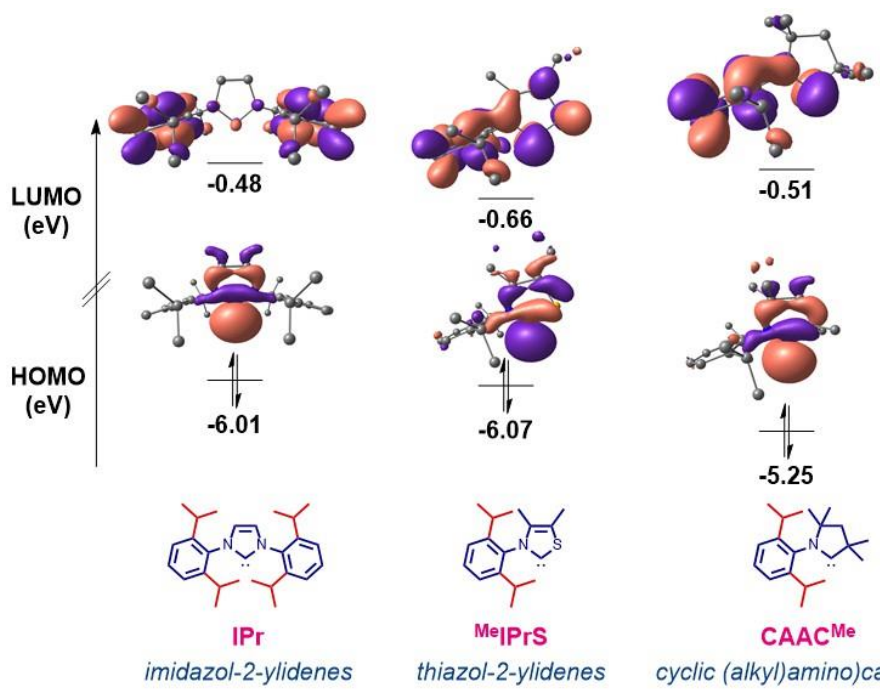

cyclic (alkyl)amino)carbenes

Figure 5. HOMO and LUMO energy levels (eV) calculated at B3LYP 6-311++g(d,p). See SI for details. 
Discussion. In conclusion, although N-heterocyclic carbenes represent a dominant direction in ligand development in the last 20 years, the majority of efforts in catalysis have been almost exclusively limited to N-aryl-imidazolylidenes, such as IPr. In this study, we reported the first study on steric and electronic properties of thiazol-2-ylidenes. We presented comprehensive evaluation of steric, electrondonating and $\pi$-accepting properties as well as structural characterization of $\mathrm{Ag}(\mathrm{I})$ and $\mathrm{Cu}(\mathrm{I})$ complexes of $\mathrm{N}$-aryl thiazol-2-ylidenes. The ring dissymmetry and enhanced $\pi$-electrophilicity result in a class of highly active carbene ligands that supersede imidazol-2-ylidenes. We showed that this mode of catalysis can be applied to late-stage drug functionalization to furnish attractive building blocks for medicinal chemistry. The unique electronic properties in combination with steric differentiation in a "half umbrella" shape with the single nitrogen $\mathrm{N}$-wingtip oriented toward the metal open a plethora of possibilities in the development of enhanced arsenal of thiazol-2-ylidene ligands of broad interest in chemical synthesis.

\section{Methods}

General procedure for the synthesis of $\operatorname{Ag}(\mathbf{I})$ Complexes. An oven-dried vial equipped with a stir bar was charged with $\mathrm{N}$-Aryl thiazol-2-ylidenes carbene precursors (1.0 equiv), $\mathrm{Ag}_{2} \mathrm{O}$ (typically, 0.5 equiv) and $\mathrm{NaCl}$ (typically, 2.0 equiv). The reaction mixture was placed under a positive pressure of argon and subjected to three evacuation/backfilling cycles under high vacuum. DCM (typically, $0.04 \mathrm{M}$ ) was added and the reaction mixture was stirred away from light overnight at room temperature. The reaction mixture was filtered through Celite with DCM as eluent and concentrated under reduced pressure, and dried under high vacuum to afford silver(I) complex

General procedure for the cyclisation of propargylic amides. An oven-dried vial equipped with a stir bar was charged with propargylic amides (1.0 equiv), Ag catalyst $\mathbf{4 c}$ (typically, $1.0 \mathrm{~mol} \%)$. The reaction mixture was placed under a positive pressure of argon and subjected to three evacuation/backfilling cycles under high vacuum. Then AcOH (typically, 1.0 equiv) and DCM (typically, $1.0 \mathrm{M}$ ) was added 
and the reaction mixture was stirred at room temperature for $8 \mathrm{~h}$. The volatiles were removed in vacuo and the products were purified by column chromatography on silica gel (EtOAc/hexanes).

\section{Data Availability}

Experimental procedures, characterization data, computational details, cif files of $\mathbf{4 a - 4 c , 5 a}$ and 9ad, coordinates and energies are available within this article and its Supplementary Information. Data are also available from the corresponding author on request.

\section{References}

1. Arduengo, A. J., III; Harlow, R. L.; Kline, M. A Stable Crystalline Carbene. J. Am. Chem. Soc. 113, 361-363 (1991).

2. Herrmann, W. A.; Elison, M.; Fischer, J.; Köcher, C.; Artus, G. R. J. Metal Complexes of NHeterocyclic Carbenes-A New Structural Principle for Catalysts in Homogeneous Catalysis. Angew. Chem. Int. Ed. 34, 2371-2374 (1995).

3. For the discovery of the first stable acyclic carbene, see: (a) Igau, A.; Grutzmacher, H.; Baceiredo, A.; Bertrand, G. Analogous $\alpha, \alpha^{\prime}$-bis-carbenoid, triply bonded species: synthesis of a stable $\lambda^{3}$ phosphino carbene- $\lambda^{5}$-phosphaacetylene. J. Am. Chem. Soc. 110, 6463-6466 (1988). (b) Martin, D.; Melaimi, M.; Soleilhavoup, M.; Bertrand, G. A Brief Survey of Our Contribution to Stable Carbene Chemistry. Organometallics 30, 5304-5313 (2011).

4. For selected reviews and monographs, see: (a) Bellotti, P.; Koy, M.; Hopkinson, M. N.; Glorius, F. Recent advances in the chemistry and applications of N-heterocyclic carbenes. Nat. Rev. Chem. 5, 711-725 (2021). (b) Hopkinson, M. N.; Richter, C.; Schedler, M.; Glorius, F. An overview of Nheterocyclic carbenes. Nature 510, $485-496$ (2014). (c) Cazin, C. S. J., Ed. N-Heterocyclic Carbenes in Transition Metal Catalysis (Springer: New York, 2011). (d) Diez-Gonzalez, S., Ed. $N$ Heterocyclic Carbenes: From Laboratory Curiosities to Efficient Synthetic Tools (RSC: Cambridge, 2016). (e) Huynh, H. V. The Organometallic Chemistry of N-Heterocyclic Carbenes (Wiley: 
Hoboken, 2017). (f) Hermann, W. A. N-Heterocyclic Carbenes: A New Concept in Organometallic Catalysis. Angew. Chem. Int. Ed. 41, 1290-1309 (2002). (g) Peris, E. Smart N-Heterocyclic Carbene Ligands in Catalysis. Chem. Rev. 118, 9988-10031 (2018). (h) Iglesias, M.; Oro, L. A. A leap forward in iridium-NHC catalysis: new horizons and mechanistic insights. Chem. Soc. Rev. 47, 2772-2808 (2018). (i) Danopoulos, A. A.; Simler, T.; Braunstein, P. N-Heterocyclic Carbene Complexes of Copper, Nickel, and Cobalt. Chem. Rev. 119, 3730-3961 (2019). (j) Zhao, Q.; Meng, G.; Nolan, S. P.; Szostak, M. N-Heterocyclic Carbene Complexes in C-H Activation Reactions. Chem. Rev. 120, 1981-2048 (2020).

5. (a) Jacobsen, H.; Correa, A.; Poater, A.; Costabile, C.; Cavallo, L. Understanding the M-(NHC) $(\mathrm{NHC}=$ N-heterocyclic carbene) bond. Coord. Chem. Rev. 253, 687-703 (2009). (b) Dröge, T.; Glorius, F. The Measure of All Rings: N-Heterocyclic Carbenes. Angew. Chem. Int. Ed. 49, 69406952 (2010).

6. (a) Clavier, H.; Nolan, S. P. Percent buried volume for phosphine and N-heterocyclic carbene ligands: steric properties in organometallic chemistry. Chem. Commun. 46, 841-861 (2010). (b) Gomez-Suarez, A.; Nelson, D. J.; Nolan, S. P. Quantifying and understanding the steric properties of N-heterocyclic carbenes. Chem. Commun. 53, 2650-2660 (2017).

7. (a) Vougioukalakis, G. C.; Grubbs, R. H. Ruthenium-Based Heterocyclic Carbene-Coordinated Olefin Metathesis Catalysts. Chem. Rev. 110, 1746-1787 (2010). (b) Ogba, O. M.; Warner, N. C.; O’Leary, D. J.; Grubbs, R. H. Recent advances in ruthenium-based olefin metathesis. Chem. Soc. Rev. 47, 4510-4544 (2018).

8. (a) Meijere, A.; Bräse, S.; Oestreich, M., Eds. Metal-Catalyzed Cross-Coupling Reactions and More de (Wiley: New York, 2014). (b) Molander, G. A.; Wolfe, J. P.; Larhed, M., Eds. Science of Synthesis: Cross-Coupling and Heck-Type Reactions (Thieme: Stuttgart, 2013). (c) Colacot, T. J. New Trends in Cross-Coupling: Theory and Applications (RSC: Cambridge, 2015). 
9. (a) Arduengo, A. J. III, Looking for Stable Carbenes: The Difficulty of Starting Anew. Acc. Chem. Res. 32, 913-921 (1999). (b) Huang, J.; Nolan, S. P. Efficient Cross Coupling of Aryl Chlorides with Aryl Grignard Reagents (Kumada-Corriu Reaction) Mediated by a Palladium/Imidazolium Chloride System. J. Am. Chem. Soc. 121, 9889-9890 (1999). (c) Arduengo, III, A. J.; Krafczyk, R.; Schmutzler, R.; Craig, H. A.; Goerlich, J. R.; Marshall, W. J.; Unverzagt, M. Imidazolylidenes, imidazolinylidenes and imidazolidines. Tetrahedron 55, 14523-14534 (1999).

10. Munz, D. Pushing Electrons - Which Carbene Ligand for Which Application? Organometallics 37, 275-289 (2018).

11. (a) Lavallo, V.; Canac, Y.; Präsang, C.; Donnadieu, B.; Bertrand, G. Stable Cyclic (Alkyl)Amino)Carbenes as Rigid or Flexible, Bulky, Electron-Rich Ligands for Transition-Metal Catalysis: A Quaternary Carbon Atom Makes the Difference. Angew. Chem. Int. Ed. 44, 5705 (2005). (b) Martin, D.; Lassauque, N.; Donnadieu, B.; Bertrand, G. A Cyclic Diaminocarbene with a Pyramidalized Nitrogen Atom: A Stable N-Heterocyclic Carbene with Enhanced Electrophilicity. Angew. Chem. 51, 6172-6175 (2012). (c) Weinstein, C.; Junor, G. P.; Tolentino, D. R.; Jazzar, R.; Melaimi, M.; Bertrand, G. Highly Ambiphilic Room Temperature Stable Six-Membered Cyclic (Alkyl)(amino)carbenes. J. Am. Chem. Soc. 140, 9255-9260 (2018). For reviews, see: (d) Melaimi, M.; Soleihavoup, M.; Bertrand, G. Angew. Chem. Int. Ed. 49, 8810-8849 (2010). (e) Soleilhavoup, M.; Bertrand, G. Cyclic (Alkyl)(Amino)Carbenes (CAACs): Stable Carbenes on the Rise. Acc. Chem. Res. 48, 256-266 (2015). (f) Melaimi, M.; Jazzar, R.; Soleilhavoup, M.; Bertrand, G. Cyclic (Alkyl)(amino)carbenes (CAACs): Recent Developments. Angew. Chem. Int. Ed. 56, 10046-10068 (2017). (g) Jazzar, R.; Soleilhavoup, M.; Bertrand, G. Cyclic (Alkyl)- and (Aryl)-(amino)carbene Coinage Metal Complexes and Their Applications. Chem. Rev. 120, 4141-4168 (2020). (h) Morvan, J.; Mauduit, M.; Bertrand, G.; Jazzar, R. Cyclic (Alkyl)(amino)carbenes (CAACs) in Ruthenium Olefin Metathesis. ACS Catal. 11, 1714-1748 (2021).

12. (a) Hudnall, T. W.; Bielawski, C. W.; An N,N'-Diamidocarbene: Studies in C-H Insertion, Reversible Carbonylation, and Transition-Metal Coordination Chemistry. J. Am. Chem. Soc. 131, 
16039-16041 (2009). (b) Moerdyk, J. P.; Bielawski, C. W. Diamidocarbenes as versatile and reversible $[2+1]$ cycloaddition reagents. Nat. Chem. 4, 275-280 (2012). (c) Moerdyk, J. P.; Schilter, D.; Bielawski, C. W. N,N'-Diamidocarbenes: Isolable Divalent Carbons with Bona Fide Carbene Reactivity. Acc. Chem. Res. 49, 1458-1468 (2016).

13. (a) Mathew, P.; Neels, A.; Albrecht, M. 1,2,3-Triazolylidenes as Versatile Abnormal Carbene Ligands for Late Transition Metals. J. Am. Chem. Soc. 130, 13534-13535 (2008). (b) Donnelly, K. F.; Petronilho, A.; Albrecht, M. Application of 1,2,3-triazolylidenes as versatile NHC-type ligands: synthesis, properties, and application in catalysis and beyond. Chem. Commun. 49, 1145-1159 (2013). (c) Guisado-Barrios, G.; Soleilhavoup, M.; Bertrand, G. 1H-1,2,3-Triazol-5-ylidenes: Readily Available Mesoionic Carbenes. Acc. Chem. Res. 51, 3236-3244 (2018).

14. (a) Schuster, O.; Yang, L. R.; Raubenheimer, H. G.; Albrecht, M. Beyond Conventional NHeterocyclic Carbenes: Abnormal, Remote, and Other Classes of NHC Ligands with Reduced Heteroatom Stabilization. Chem. Rev. 109, 3445-3478 (2009). (b) Crabtree, R. H. Abnormal, Mesoionic and Remote N-Heterocyclic Carbene Complexes. Coord. Chem. Rev. 257, 755-766 (2013). (c) Vivancos, Á.; Segarra, C.; Albrecht, M. Mesoionic and Related Less HeteroatomStabilized N-Heterocyclic Carbene Complexes: Synthesis, Catalysis, and Other Applications. Chem. Rev. 118, 9493-9586 (2018). (d) Sau, S. C.; Hota, P. K.; Mandal, S. K.; Soleilhavoupb, M.; Bertrand, G. Stable Abnormal N-Heterocyclic Carbenes and Their Applications. Chem. Soc. Rev. 49, 1233-1252 (2020).

15. For further examples of unconventional carbenes, see: (a) Krahulic, K. E.; Enright, G. D.; Parvez, M.; Roesler, R. A Stable N-Heterocyclic Carbene with a Diboron Backbone. J. Am. Chem. Soc. 127, 4142-4143 (2005). (b) Despagnet-Ayoub, E.; Grubbs, R. H. A Stable Four-Membered NHeterocyclic Carbene. J. Am. Chem. Soc. 126, 10198-10199 (2004). (c) Chen, W. C.; Shih, W. C.; Jurca, T.; Zhao, L.; Andrada, D. M.; Peng, C. J.; Chang, C. C.; Liu, S. K.; Wang, Y. P.; Wen, Y. S.; Yap, G. P. A.; Hsu, C. P.; Frenking, G.; Ong, T. G. Carbodicarbenes: Unexpected $\pi$-Accepting Ability during Reactivity with Small Molecules. J. Am. Chem. Soc. 139, 12830-12836 (2017). 
16. Arduengo, III, A. J.; Goerlich, J. R.; Marshall, W. J. A Stable Thiazol-2-ylidene and Its Dimer. Liebigs Ann. 365-374 (1997).

17. Vougioukalakis, G. C.; Grubbs, R. H. Synthesis and Activity of Ruthenium Olefin Metathesis Catalysts Coordinated with Thiazol-2-ylidene Ligands. J. Am. Chem. Soc. 130, 2234-2245 (2008).

18. Limited examples of N-alkyl (benzo)thiazol-2-ylidenes have been reported: (a) Huynh, H. V.; Meier, N.; Pape, T; Hahn, F. E. Benzothiazolin-2-ylidene Complexes of Iridium(I) Organometallics 25, 3012-3018 (2006). (b) Ding, N.; Hor, T. S. A. Ruthenium(ii) N,S-heterocyclic carbene complexes and transfer hydrogenation of ketones. Dalton Trans. 39, 10179-10185 (2010). (c) Ding, N.; Zhang, W.; Hor, T. S. A. One-step entry to olefin-tethered N,S-heterocyclic carbene complexes of ruthenium with mixed ligands. Dalton Trans. 41, 5988-5994 (2012).

19. (a) Ishii, T.; Ota, K.; Nagao, K.; Ohmiya, H.; N-Heterocyclic Carbene-Catalyzed Radical Relay Enabling Vicinal Alkylacylation of Alkenes J. Am. Chem. Soc. 141, 14073-14077 (2019). (b) Ishii, T.; Kakeno, Y.; Nagao, K.; Ohmiya, H.; N-Heterocyclic Carbene-Catalyzed Decarboxylative Alkylation of Aldehydes. J. Am. Chem. Soc. 141, 3854-3858 (2019). For select examples of thiazol2-ylidenes in organocatalysis, see: (c) Hirano, K.; Biju, A. T.; Piel, I.; Glorius, F. N-Heterocyclic Carbene-Catalyzed Hydroacylation of Unactivated Double Bonds J. Am. Chem. Soc. 131, 1419014191 (2009). (d) Biju, A. T.; Wurz, N. E.; Glorius, F. N-Heterocyclic Carbene-Catalyzed Cascade Reaction Involving the Hydroacylation of Unactivated Alkynes. J. Am. Chem. Soc. 132, 5970-5971 (2010). (e) Biju, A. T.; Glorius, F. Intermolecular N-Heterocyclic Carbene Catalyzed Hydroacylation of Arynes. Angew. Chem. Int. Ed. 49, 9761-9764 (2010). (f) Piel, I.; Pawelczyk, M. D.; Hirano, K.; Fröhlich, R.; Glorius, F. A Family of Thiazolium Salt Derived N-Heterocyclic Carbenes (NHCs) for Organocatalysis: Synthesis, Investigation and Application in Cross-Benzoin Condensation. Eur. J. Org. Chem. 5475-5484 (2011).

20. Finney, E. E.; Ogawa, K. A.; Boydston, A. J. Organocatalyzed Anodic Oxidation of Aldehydes. J. Am. Chem. Soc. 134, 12374-12377 (2012). 
21. (a) Paul, M.; Sudkaow, P.; Wessels, A.; Schlörer, N. E.; Neudörfl, J. M.; Berkessel, A. Breslow Intermediates from Aromatic N-Heterocyclic Carbenes (Benzimidazolin-2-ylidenes, Thiazolin-2ylidenes). Angew. Chem. Int. Ed. 57, 8310-8315 (2018). (b) Paul, M.; Neudörfl, J. M.; Berkessel, A. Breslow Intermediates from a Thiazolin-2-ylidene and Fluorinated Aldehydes: XRD and SolutionPhase NMR Spectroscopic Characterization. Angew. Chem. Int. Ed. 58, 10596-10600 (2019).

22. Kluger, R.; Tittmann, K.; Thiamin Diphosphate Catalysis: Enzymic and Nonenzymic Covalent Intermediates. Chem. Rev. 108, 1797-1833 (2008).

23. Breslow, R. On the Mechanism of Thiamine Action. IV. Evidence from Studies on Model Systems. J. Am. Chem. Soc. 80, 3719-3726 (1958).

24. For further reviews on types of cyclic carbenes and related species, see: (a) Bourissou, D.; Guerret, O.; Gabbaï, F. P.; Bertrand, G. Stable Carbenes. Chem. Rev. 100, $39-92$ (2000). (b) Hahn, F. E.; Jahnke, M. C. Heterocyclic Carbenes: Synthesis and Coordination Chemistry. Angew. Chem. Int. Ed. 47, 3122-3172 (2008). (c) Soleilhavoup, M.; Bertrand, G. Stable Carbenes, Nitrenes, Phosphinidenes, and Borylenes. Chem 5, 1275-1282 (2020).

25. Gusev, D. G. Donor Properties of a Series of Two-Electron Ligands. Organometallics 28, 763-770 (2009).

26. (a) Shi, S.; Nolan, S. P.; Szostak, M. Well-Defined Palladium(II)-NHC (NHC = N-Heterocyclic Carbene) Precatalysts for Cross-Coupling Reactions of Amides and Esters by Selective Acyl CO-X (X = N, O) Cleavage. Acc. Chem. Res. 51, 2589-2599 (2018). (b) Zhao, Q.; Meng, G.; Li, G.; Flach, C.; Mendelsohn, R.; Lalancette, R.; Szostak, R; Szostak, M. IPr\# - highly hindered, broadly applicable N-heterocyclic carbenes. Chem. Sci. 12, $10583-10589$ (2021). (c) Zhou, T.; Ma, S.; Nahra, F.; Obled, A. M. C.; Poater, A.; Cavallo, L.; Cazin, C. S. J.; Nolan, S. P.; Szostak, M. $[\mathrm{Pd}(\mathrm{NHC})(\mu-\mathrm{Cl}) \mathrm{Cl}]_{2}$ : Versatile and Highly Reactive Complexes for Cross-Coupling Reactions that Avoid Formation of Inactive Pd(I) Off-Cycle Products. iScience 23, 101377 (2020). (d) Xia, Q.; Shi, S.; Gao, P.; Lalancette, R.; Szostak, R.; Szostak, M. [(NHC)PdCl2(Aniline)] Complexes: Easily 
Synthesized, Highly Active Pd(II)-NHC Precatalysts for Cross-Coupling Reactions. J. Org. Chem.

86, 15648-15657 (2021). (e) Lei, P.; Meng, G.; Szostak, M. General Method for the SuzukiMiyaura Cross-Coupling of Amides Using Commercially Available, Air- and Moisture-Stable Palladium/NHC (NHC = N-Heterocyclic Carbene) Complexes. ACS Catal. 7, 1960-1965 (2017). (f) Lei, P.; Meng, G.; Shi, S.; Ling, Y.; An, J.; Szostak, R.; Szostak, M. Suzuki-Miyaura CrossCoupling of Amides and Esters at Room Temperature: Correlation with Barriers to Rotation around C-N and C-O Bonds. Chem. Sci. 8, 6525-6530 (2017). (g) Chen, C.; Liu, F. S.; Szostak, M. BIAN-NHC Ligands in Transition-Metal-Catalysis: A Perfect Union of Sterically Encumbered, Electronically Tunable N-Heterocyclic Carbenes? Chem. Eur. J. 27, 4478-4499 (2021).

27. (a) Wang, Z.; Tzouras, N. V.; Nolan, S. P.; Bi, X. Silver N-Heterocyclic Carbenes: Emerging Powerful Catalysts. Trends Chem. 3, 674-685 (2021). (b) Bi, X. "Silver Complexes in Organic Transformations" In Silver Catalysis in Organic Synthesis; Li, C. J.; Bi, X., Eds., Wiley-VCH: Weinheim, pp. 661-722 (2019).

28. Falivene, L.; Cao, Z.; Petta, A.; Serra, L.; Poater, A.; Oliva, R.; Scarano, V.; Cavallo, L. Towards the Online Computer-Aided Design of Catalytic Pockets. Nat. Chem. 11, 872-879 (2019).

29. Mankad, N. P.; Gray, T. G.; Laitar, D. S.; Sadighi, J. P. Synthesis, Structure, and $\mathrm{CO}_{2}$ Reactivity of a Two-Coordinate (Carbene)copper(I) Methyl Complex. Organometallics 23, 1191-1193 (2004).

30. Huynh, H. V. Electronic Properties of N-Heterocyclic Carbenes and Their Experimental Determination. Chem. Rev. 118, 9457-9492 (2018).

31. (a) Vummaleti, S. V. C.; Nelson, D. J.; Poater, A.; Gomez-Suarez, A.; Cordes, D. B.; Slawin, A. M. Z.; Nolan, S. P.; Cavallo, L. What can NMR spectroscopy of selenoureas and phosphinidenes teach us about the $\pi$-accepting abilities of N-heterocyclic carbenes? Chem. Sci. 6, 1895-1904 (2015). (b) Liske, A.; Verlinden, K.; Buhl, H.; Schaper, K.; Ganter, C. Determining the $\pi$-Acceptor Properties of N-Heterocyclic Carbenes by Measuring the ${ }^{77} \mathrm{Se}$ NMR Chemical Shifts of Their Selenium Adducts. Organometallics 32, 5269-5272 (2013). (c) Junor, G. P.; Lorkowski, J.; Weinstein, C. M.; 
Jazzar, R.; Pietraszuk, C. Bertrand, G. The Influence of $\mathrm{C}\left(\mathrm{sp}^{3}\right) \mathrm{H}-$ Selenium Interactions on the ${ }^{77} \mathrm{Se}$ NMR Quantification of the $\pi$-Accepting Properties of Carbenes. Angew. Chem. Int. Ed. 59, 2202822033 (2020). For phosphinidene method, see: (d) Back, O.; Henry-Ellinger, M.; Martin, C. D.; Martin, D.; Bertrand, G. ${ }^{31} \mathrm{P}$ NMR Chemical Shifts of Carbene-Phosphinidene Adducts as an Indicator of the $\pi$-Accepting Properties of Carbenes. Angew. Chem. Int. Ed. 52, 2939-2943 (2013).

32. Meng, G.; Kakalis, L.; Nolan, S. P.; Szostak, M. A Simple ${ }^{1}$ H NMR Method for Determining the $\sigma-$ Donor Properties of N-Heterocyclic Carbenes. Tetrahedron Lett. 60, 378-381 (2019).

33. Zhang, H. Z.; Zhao, Z. L.; Zhou, C. H. Recent Advances in Oxazole-Based Medicinal Chemistry. Eur. J. Med. Chem. 144, 444-492 (2018).

34. (a) Wong, V. H. L.; Vummaleti, S. V. C.; Cavallo, L.; White, A. J. P.; Nolan, S. P.; Hii, K. K. M. Synthesis, Structure and Catalytic Activity of NHC-Ag(I) Carboxylate Complexes. Chem. Eur. J. 22, 13320-13327 (2016). (b) Su, H. L.; Pérez, L. M.; Lee, S. J.; Reibenspies, J. H.; Bazzi, H. S.; Bergbreiter, D. E. Studies of Ligand Exchange in N-Heterocyclic Carbene Silver(I) Complexes. Organometallics 31, 4063-4071 (2012).

35. The catalysis is consistent with the dissociation of $[\mathrm{NHC}-\mathrm{M}] \mathrm{X}$ to $[\mathrm{NHC}-\mathrm{M}]^{+}$and $[\mathrm{NHC}-\mathrm{M}]^{+}$as the active catalyst. $[\mathrm{NHC}-\mathrm{Ag}]_{2} \mathrm{ClO}_{4}(\mathrm{NHC}=\mathbf{3 a}-\mathbf{3 d})$ are bench-stable and easy to handle. However, we also prepared and tested thiazol-2-ylidene $[\mathrm{NHC}-\mathrm{Ag}]_{2} \mathrm{PF}_{6}(\mathrm{NHC}=\mathbf{3 c}, 90 \%$ yield $)$, imidazol-2ylidene $[\mathrm{NHC}-\mathrm{Ag}]_{2} \mathrm{ClO}_{4}(\mathrm{NHC}=\mathrm{IPr},<5 \%$ yield, IMes, 30\% yield $)$ and imidazol-2-ylidene $[\mathrm{NHC}-$ $\mathrm{Ag}]_{2} \mathrm{PF}_{6}(\mathrm{NHC}=\mathrm{IPr},<5 \%$ yield, IMes, $21 \%$ yield $)$. These results further demonstrate the superior effect of N-aryl thiazol-2-ylidene Ag(I) complexes.

36. For select recent examples of M-NHCs in electrophilic functionalization, see: (a) Itoh, T.; Shimizu, Y.; Kanai, M. Ligand-Enabled, Copper-Catalyzed Regio- and Stereoselective Synthesis of Trialkylsubstituted Alkenylboronates from Unactivated Internal Alkynes. J. Am. Chem. Soc. 138, 7528-7531 (2016). (b) Lee. M. T.; Goodstein, M. B.; Lalic, G. Synthesis of Isomerically Pure (Z)Alkenes from Terminal Alkynes and Terminal Alkenes: Silver-Catalyzed Hydroalkylation of 
Alkynes. J. Am. Chem. Soc. 141, 17086-17091 (2019). (c) Cheng, L.-J.; Mankad, N. P. CopperCatalyzed Carbonylative Coupling of Alkyl Halides. Acc. Chem. Res. 54, 2261-2274 (2021). (d) Ozawa, Y.; Endo, K.; Ito, H. Regio- and Stereoselective Synthesis of Multi-Alkylated Allylic Boronates through Three-Component Coupling Reactions between Allenes, Alkyl Halides, and a Diboron Reagent. J. Am. Chem. Soc. 143, 13865-13877 (2021). (e) García-Fernández, P. D.; Iglesias-Sigüenza, J.; Rivero-Jerez, P. S.; Díez, E.; Gómez-Bengoa, E.; Fernández, R.; Lassaletta, J. M. AuI-Catalyzed Hydroalkynylation of Haloalkynes J. Am. Chem. Soc. 142, 16082-16089 (2020).

\section{Acknowledgements}

J.Z. thanks National Natural Science Foundation of China (No. 22179075). R.F. thanks National Natural Science Foundation of China (No. 21672090). M.S. thanks Rutgers University and the NSF (CAREER CHE-1650766) for support. We thank the Wroclaw Center for Networking and Supercomputing (grant number WCSS159).

\section{Author contributions}

J.Z., R.F. and M.S. conceived the concept and designed the experiments. T.L., X.L., A.L. X.L., Z.W., R.W. and Y.M. conducted the chemical reactions described in the manuscript. J.Z., R.F. and M.S. wrote the manuscript and all authors contributed to the reading and editing of the manuscript. T.L. compiled the Supplementary Information.

\section{Additional information}

Supplementary information is available in the online version of the paper. Reprints and permission information is available online at www.nature.com/reprints. Correspondence and requests for materials should be addressed to J.Z., R.F. and M.S.

\section{Competing financial interests}

The authors declare no competing financial interests. 
Abstract

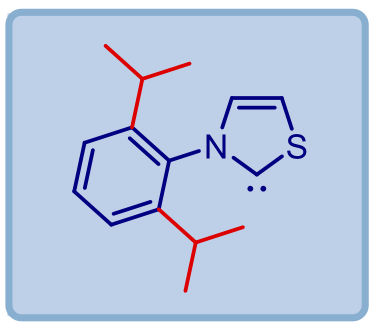

$\mathrm{N}$-aryl thiazol-2-ylidenes

$\boldsymbol{\Delta} \pi$-accepting $\boldsymbol{\sigma} \sigma$-donating - sterically-distinct

• "half umbrella" shaped 


\section{Supplementary Files}

This is a list of supplementary files associated with this preprint. Click to download.

- Supportinglnformation.pdf 